\title{
Psychometric properties of the Child Anxiety Life Interference Scale - Preschool
}

\section{Version}

Tamsyn J Gilbertson ${ }^{\mathrm{a}, \mathrm{b}}$ MSc, Amy J Morgan ${ }^{\mathrm{c}, \mathrm{d}} \mathrm{PhD}$, Ronald M Rapee ${ }^{\mathrm{e}} \mathrm{MSc}(\mathrm{Psych}) \mathrm{PhD}$, Heidi J Lynehame MClinPsych PhD, Jordana K Bayer ${ }^{\text {b,d,f }}$ MClinPsych PhD

Email Addresses: Tamsyn J Gilbertson, tamsyn.gilbertson@gmail.com; Amy J Morgan, ajmorgan@unimelb.edu.au; Ronald M Rapee, ron.rapee@mq.edu.au; Heidi J Lyneham, heidi.1yneham@mq.edu.au; Jordana K Bayer, J.Bayer@1atrobe.edu.au

Affiliations: ${ }^{a}$ Melbourne School of Psychological Sciences, University of Melbourne,

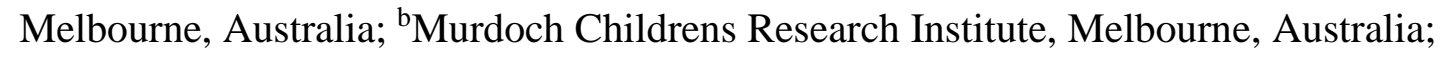
${ }^{c}$ Melbourne School of Population and Global Health, University of Melbourne, Melbourne, Australia; ${ }^{\mathrm{d} S c h o o l}$ of Psychology and Public Health, La Trobe University, Melbourne, Australia; ${ }^{\mathrm{e} C e n t r e}$ for Emotional Health, Macquarie University, Sydney, Australia; ${ }^{f}$ Department of Paediatrics, University of Melbourne, Melbourne, Australia.

Address correspondence to: Tamsyn J Gilbertson, Melbourne School of Psychological Sciences, Redmond Barry Building, University of Melbourne, Parkville, VIC 3010, Australia, [tamsyn.gilbertson@gmail.com], +61 424069186

Word count: Abstract 189; Text 6,291; 5 Tables 


\begin{abstract}
Despite growing recognition of childhood anxiety as a common and often debilitating clinical concern, we have limited knowledge of the particular ways in which anxiety interferes with daily life for young children who have not yet entered formal schooling. The present study evaluated the psychometric properties of the Child Anxiety Life Interference Scale Preschool Version (CALIS-PV). The CALIS-PV is a brief (18 item) parent-report measure of the impacts of a young child's anxiety on their own life and that of her or his parent. Participants were 784 parents of a child aged 3 to 7 years, who completed the CALIS-PV as a part of the follow-up assessment battery for two anxiety prevention trials targeted at preschool children with temperamental inhibition. Confirmatory factor analysis supported three CALISPV factors reflecting anxiety-related life interference at home, outside home and on parent life. The three factors showed good internal consistency and good convergent and divergent validity, and successfully differentiated children with and without an anxiety diagnosis. Findings provide initial support for the CALIS-PV as a reliable and valid measure of the daily life impacts of childhood anxiety for preschool-aged children and their parents.
\end{abstract}

Keywords: preschool; child anxiety; life interference; quality of life; assessment 


\section{Introduction ${ }^{1}$}

Anxiety disorders are the most common class of mental disorder across development (Kessler et al., 2005; Whalen, Sylvester, \& Luby, 2017). These disorders tend to begin very early in life, with a median age of onset of 6 years for affected youth (Merikangas et al., 2010). Although epidemiological research focusing on young children is limited, emerging evidence indicates that between 10 and $20 \%$ of preschool-aged children in the community meet criteria for at least one anxiety disorder (Sylvester \& Pine, 2016). Anxiety disorders show concerning stability over the preschool period, with one study indicating that $34 \%$ of children with an anxiety disorder at age 3 will continue to meet criteria for the diagnosis at age 6 (Bufferd, Dougherty, Carlson, Rose, \& Klein, 2012; Bufferd et al., 2016). In the longer term, childhood anxiety disorders often follow a chronic or recurring course into adolescence and adulthood (Bittner et al., 2007; Goodwin, Fergusson, \& Horwood, 2004), and confer significant risk for the development of secondary conditions such as depression and substance abuse (Woodward \& Fergusson, 2001). Childhood anxiety warrants attention not only because of its prevalence and persistence, but also because of its considerable immediate impact on the daily lives of affected children and their families (Langley, Bergman, McCracken, \& Piacentini, 2004).

Symptom-induced distress or impairment is a key diagnostic criterion for all anxiety diagnoses listed within recent editions of the Diagnostic and Statistical Manual of Mental Disorders (i.e., DSM-IV and DSM-5; American Psychiatric Association, 2000, 2013). This

\footnotetext{
${ }^{1}$ List of abbreviations: Anxiety Disorders Interview Schedule for Children for DSM-IV, ADIS-C/P; Child Anxiety Impact Scale, CAIS; Child Anxiety Life Interference Scale, CALIS; Child Anxiety Life Interference Scale - Preschool Version, CALIS-PV; Child Sheenan Disability Scale, CSDS; Children's Moods Fears and Worries Questionnaire, CMFWQ; Diagnostic and Statistical Manual of Mental Disorders, DSM; Cool Little Kids, CLK; Cool Little Kids Online, CLK-Online; Online Assessment of Preschool Anxiety, OAPA; Revised Preschool Anxiety Scale, PAS-R; Strengths and Difficulties Questionnaire, SDQ.
} 
'impairment criterion' is routinely highlighted as a primary means of differentiating normative childhood fears from pathological anxiety (Beesdo, Knappe, \& Pine, 2009; Rapee \& Coplan, 2010). Impairment in daily life certainly serves as a primary motivation for families seeking treatment for child mental health concerns (Jongerden, Simon, Bodden, Dirksen, \& Bögels, 2015; Wichstrøm, Belsky, Jozefiak, Sourander, \& Berg-Nielsen, 2014), and represents a significant predictor of the longer-term trajectory of child mental disorders (Angold, Costello, Farmer, Burns, \& Erkanli, 1999; Pickles et al., 2001; Stringaris \& Goodman, 2013). Assessment of impairment is therefore integral both to the identification and conceptualization of child anxiety cases, and to the development and evaluation of treatments that target clients' real-life concerns (Fabiano \& Pelham, 2016; Rapee, Bögels, van der Sluis, Craske, \& Ollendick, 2012). Research to date has however tended to focus on the assessment and classification of symptoms of anxiety, with less attention paid to evaluating the impacts of these symptoms on daily life functioning (Muroff \& Ross, 2011; Swan \& Kendall, 2016). This is particularly evident for children younger than school age, where new developmentally sensitive diagnostic and symptom assessments have only recently facilitated recognition of anxiety as a potentially serious concern (Warren, 2007).

Studies focussing on school-aged children and adolescents have demonstrated significant negative impacts of anxiety on school performance and participation (Bernstein, Bernat, Davis, \& Layne, 2008; Mazzone et al., 2007; Muris \& Meesters, 2002; Mychailyszyn, Mendez, \& Kendall, 2010), peer relationships (Hoff et al., 2015; La Greca \& Lopez, 1998), and family functioning (Essau, Lewinsohn, Olaya, \& Seeley, 2014; Thompson-Hollands, Kerns, Pincus, \& Comer, 2014). Anxiety may have similar negative impacts for preschoolaged children. Incessant worry or fearfulness in the preschool environment may impair concentration and inhibit help-seeking, resulting in delayed learning relative to non-anxious peers (Wood, 2007). In the social sphere, anxious withdrawal may prevent initiation of social 
play, limiting opportunities to practice social skills and develop friendships (Coplan, DeBow, Schneider, \& Graham, 2009; Gazelle \& Druhen-Shell, 2017). Preschool anxiety may also impact significantly on parent wellbeing and family relationships, as parents either battle to engage their young child in anxiety-provoking activities (e.g., sleeping in their own bed or attending preschool), or modify family routines to protect their child from distress (ToweGoodman, Franz, Copeland, Angold, \& Egger, 2014).

In recent years a small selection of measures have been developed to assess the multiple potential impacts of broadband anxiety symptoms on daily life functioning for school-aged children and adolescents; namely the Child Sheenan Disability Scale (CSDS; Whiteside, 2009), the Child Anxiety Impact Scale (CAIS; Langley et al., 2004; 2013), and the Child Anxiety Life Interference Scale (CALIS; Lyneham et al., 2013). For example, CALIS was developed to assess the extent to which anxiety symptoms interfere with a child's daily life functioning within the key domains of school, peer relationships and family life, within a brief child- and parent-report format. The parent-report version of the CALIS includes just 16 items that assess the impacts of a child's anxiety on their own life and that of his or her parent. Exploratory factor analysis of the measure with a clinical sample of 622 anxious children aged 6 to 17 years suggested three subscales capturing anxiety-related life interference at home, outside home and on parent life (Lyneham et al., 2013). Identified subscales were sensitive to treatment response, and showed good convergent and divergent validity (correlating highly with measures of internalizing symptoms and less highly with a measure of externalizing symptoms).

Given the marked shifts in role demands that occur with the entry to school, a tailored measure of anxiety life interference is required to adequately capture the specific impacts of anxiety during the preschool period. To address their immediate need for such a measure, Kennedy, Rapee, and Edwards (2009) adapted the parent-report CALIS for use in their 
anxiety prevention trial targeted at children aged 3 to 5 years with temperamental inhibition. Temperamental inhibition is a key early marker of risk for anxiety disorders, particularly social anxiety disorder (Clauss \& Blackford, 2012; Paulus, Backes, Sander, Weber, \& von Gontard, 2015), and is characterized by a pervasive tendency toward fearfulness and withdrawal in response to novelty. By preschool age, this temperamental trait is expressed primarily as 'shy' or reticent reactions to unfamiliar people and social situations (Kagan, Reznick, \& Snidman, 1988; Rimm-Kaufman \& Kagan, 2005). Thus, Kennedy et al.’s (2009) preschool version of the CALIS (CALIS-PV) assessed impacts of a child's "anxiety or shyness" on the parent and child's life. The CALIS-PV showed good internal consistency and sensitivity to treatment effects in the original trial sample (Kennedy et al., 2009) and continues to be used as a treatment outcome measure in anxiety prevention trials for at-risk preschoolers (Bayer et al., 2011; Fisak, 2014; Morgan, Rapee, \& Bayer, 2016; Morgan et al., 2017). However, the CALIS-PV has yet to be validated for use with preschool-aged children and, to our knowledge, no alternative measure has been developed to assess the various daily life impacts of anxiety during the preschool period. A validation of the CALIS-PV is therefore urgently required to inform its use in future research.

The aim of the present study was to test the psychometric properties of the CALIS-PV using data obtained from two anxiety prevention trials targeted at temperamentally inhibited preschool-aged children; Cool Little Kids (CLK; Bayer et al., 2011) and Cool Little Kids Online (CLK-Online; Morgan et al., 2017). We began by conducting confirmatory factor analysis (CFA) to determine whether the three-factor structure of the original school-age CALIS (Lyneham et al., 2013) provides an adequate representation of parent responses on the CALIS-PV. The adequacy of the factor structure was further tested by examining measurement invariance of the CFA model across key subgroups within the study sample (i.e., girls and boys, children with and without an anxiety diagnosis, the CLK trial sample and 
the CLK-Online trial sample). Finally, we tested the psychometric properties of the obtained CALIS-PV factors. We hypothesized that the CALIS-PV factors would demonstrate adequate internal consistency, would differentiate between children with and without an anxiety diagnosis, and would demonstrate adequate convergent validity by correlating with measures of internalizing symptoms and divergent validity by demonstrating comparatively low correlations with externalizing symptoms.

\section{Methods}

\subsection{Participants}

Participants were 784 primary caregiving parents of a temperamentally inhibited child aged 3 to 7 years $(M=5.5, S D=0.8 ; 49.2 \%$ female $)$, who were enrolled in one of two randomized controlled trials of the Cool Little Kids program in Australia. Cool Little Kids is a parenting program aimed at preventing the development of anxiety disorders in temperamentally inhibited preschool-aged children (Rapee, Kennedy, Ingram, Kennedy, \& Sweeney, 2005). The present study sample included 443 parents who completed 12-month follow-up assessments for a trial of the original group-based program (CLK; Bayer et al., 2011), and 341 parents who completed 24-week follow-up assessments for a trial of a new online adaptation of the group program (CLK-Online; Morgan et al., 2015). Follow-up data from the CLK and CLK-Online trials were used in the present study because this was the only time point to include the CALIS-PV and a diagnostic assessment of anxiety.

Diagnostic and demographic characteristics of the participants obtained from the CLK and CLK-Online trial are presented in Table 1. Almost half of children in each trial met criteria for an anxiety disorder, with social phobia being the most common diagnosis. Both trials included a significant minority of parents who had not attended university and who were experiencing financial disadvantage (as indicated by ownership of a healthcare card). It 
should be noted however that the trial samples had somewhat lower rates of both disadvantage and cultural diversity relative to the wider population from which they were drawn. For instance, the proportion of participating parents with a tertiary qualification was higher than population estimates for adults aged between 30 and 39 in Australia $(68.0 \%$ and $65.5 \%$, versus 44.2\%; Australian Bureau of Statistics, 2016). Relative to population estimates for families with children, participating families were also less likely to own a health care card $(15.9 \%$ and $13.2 \%$, versus $24 \%)$, and were more likely to speak English as their main language at home (89.6\% and 95.0\%, versus 70\%; Victorian Government, 2016).

\subsection{Measures}

2.2.1. Child Anxiety Life Interference Scale - Preschool Version (CALIS-PV; Kennedy et al., 2009)

The CALIS-PV is a parent-report measure of the impact that anxiety has on a preschool-aged child's life and that of her or his parent. The measure is freely available from www.mq.edu.au/ceh-resources. It was adapted from the validated school-age CALIS (Lyneham et al., 2013) to represent important areas of a preschool-aged child's daily life that may be impacted by anxiety (Kennedy et al., 2009). The initial CALIS-PV item set consisted of 20 questions assessing impact upon family relationships, preschool participation, social life and activities, and daily living skills. Both the parent-report CALIS and the CALIS-PV include parent interference items to acknowledge the substantial impact of child anxiety that parents report on their own life (Lyneham et al., 2013). Although the school-age CALIS includes both a parent and child self-report version, only the parent-report version was adapted for the CALIS-PV as preschool-aged children were considered too young to reliably report on the impacts of their anxiety. Additional differences from the school-age CALIS include a change in item wording to capture child preschool participation rather than school activities and performance, and three additional items assessing impacts of anxiety on the 
child's separation from parents and interactions with adults. The CALIS-PV also includes two additional parent interference items ("your free time" and "the level of harmony in the family home"), which were removed from the school-age CALIS due to high correlations with the other CALIS items (Lyneham et al., 2013).

The CALIS-PV begins with a single question asking parents to rate how much being "anxious or very shy" upsets or distresses their child. Parents are then asked to rate how much being anxious or very shy interferes with their child's life and their own life within a range of specific areas. Each item is rated on a five point Likert scale: (0) not at all, (1) only a little, (2) sometimes, (3) quite a lot, (4) a great deal. Total scores are obtained by a sum of responses.

\subsubsection{Anxiety Disorders Interview Schedule for Children for DSM-IV (ADIS-C/P, Silverman} \& Albano,1996)

The ADIS-C/P was used in the CLK trial to assess child anxiety diagnoses based on DSM-IV criteria. This semi-structured diagnostic interview was conducted with parents via telephone to assess the four most prevalent anxiety diagnoses at preschool age: separation anxiety disorder, social phobia, generalized anxiety disorder, and specific phobia (Whalen et al., 2017). The ADIS-C/P shows good to excellent inter-rater and test-retest reliability (Lyneham, Abbott, \& Rapee, 2007; Silverman, Saavedra, \& Pina, 2001; Wood, Piacentini, Bergman, McCracken, \& Barrios, 2002), and the level of agreement between telephone and face-to-face interview administration has been found to be good to excellent for individual anxiety diagnoses (kappa = 0.63-0.86; Lyneham \& Rapee, 2005). While the instrument has yet to be formally validated within a preschool sample, prior studies indicate that the interview can be reliably used to diagnose anxiety disorders in children as young as 4 years (Kennedy et al., 2009; Rapee et al., 2005).

\subsubsection{Online Assessment of Preschool Anxiety (OAPA)}


In the CLK-Online trial child anxiety diagnoses were assessed using a newly developed measure called the OAPA. The OAPA was adapted from the Youth Online Diagnostic Assessment (McLellan, Iverach, Kangas et al., 2016) for children aged 7 to 17 to provide an online assessment of anxiety diagnoses in children aged 6 years or below. Parents are asked screening questions for common child anxiety disorders (separation anxiety disorder, social phobia, generalized anxiety disorder, specific phobia), and automated rules determine whether the rest of the questions for that section are presented. For each anxiety problem, parents rate child anxiety symptoms and level of interference. Parents are also asked to describe their child's behaviors and thoughts related to each anxiety problem and write examples of anxietyrelated life interference. Responses are automatically scored for the presence or absence of a disorder on the basis of DSM-IV criteria and then all responses undergo a clinical review by a psychologist. This review checks whether parents' written descriptions are consistent with the disorder being assessed and whether the level of impairment described is clinically sufficient to warrant a diagnosis.

\subsubsection{Children's Moods Fears and Worries Questionnaire (CMFWQ; Bayer, Sanson, \&} Hemphill, 2006)

The CMFWQ was administered in the CLK trial to assess broadband internalizing (anxious/depressive) symptoms, and was used in the present study to evaluate convergent validity of the CALIS-PV. The CMFWQ is a 34-item parent-report questionnaire designed to be sensitive to internalizing symptoms in community samples of children aged 2 to 7 years. Each item is rated by the parent on a five-point Likert scale ranging from "almost never" to "almost always". Item scores are summed to provide an overall rating of internalizing symptom severity. The CMFWQ has a high level of stability over a two-year period $(r=.56$; Bayer et al., 2006), correlates highly with the Preschool Anxiety Scale $(r=.77$; Broeren \& Muris, 2008), and differentiates children with and without a DSM anxiety diagnosis (Andrijic, 
Bayer, \& Bretherton, 2013; Antonucci \& Bayer, 2017). Internal consistency in the current CLK sample was excellent $(\alpha=.95)$.

2.2.5. Revised Preschool Anxiety Scale (PAS-R; Edwards, Rapee, Kennedy, \& Spence, 2010) In the CLK-Online trial the PAS-R was administered to assess early childhood anxiety symptoms across four subscales: Generalized Anxiety, Social Phobia, Separation Anxiety, and Specific Phobias. The PAS-R total scale was used in the present study to evaluate convergent validity of the CALIS-PV. The PAS-R is an update of the Preschool Anxiety Scale (Spence, Rapee, McDonald, \& Ingram, 2001), which was originally adapted from the Spence Children's Anxiety Scale. In its revised version, the scale includes 28 items rated by the parent on a five-point Likert scale ranging from "not at all true" to "very often true". Item scores can be summed to provide an overall rating of anxiety symptom severity. The PAS-R has a high level of stability over a one year period $(r s=.60-.75)$, and shows good evidence supporting construct validity (Edwards et al., 2010). Internal consistency of the total scale in the CLK-Online sample was excellent $(\alpha=.92)$.

\subsubsection{Strengths and Difficulties Questionnaire (SDQ; Goodman, 1997; National Mental}

\section{Health Strategy, 2005)}

The SDQ is a widely-used and well validated screening tool of psychosocial problems in children (Hawes \& Dadds, 2004; Warnick, Bracken, \& Kas1, 2008). The parent-report version for children aged 4 to 10 years was administered in both the CLK and CLK-Online trials. The SDQ comprises five subscales of five items each that assess Emotional Problems, Conduct Problems, Hyperactivity, Peer Problems and Prosocial Behavior. Responses are given on a three-point Likert scale, and subscale scores are obtained by adding the relevant responses. Three SDQ subscales were selected to test convergent and divergent validity of the CALIS-PV in the present study: Emotional Problems (convergent), Conduct Problems and 
Hyperactivity (divergent). Consistent with prior validation studies of the SDQ in preschoolage samples (Kremer et al., 2015; Mieloo et al., 2012), internal consistency for the combined CLK and CLK-Online sample was modest for the Conduct Problems subscale $(\alpha=.60)$, and adequate for the Emotional Problems and Hyperactivity subscales $(\alpha=.73$ and .78 , respectively).

\subsection{Procedure}

Full details of the study procedures are reported in the CLK trial protocol (Bayer et al., 2011) and the CLK-Online trial protocol (Morgan et al., 2015). In both trials, primary caregiving participants were recruited on the basis of a child score above 30 (approximately 1.15 standard deviations above the age-adjusted norm) on the Approach-Inhibition Subscale of the parent-report Short Temperament Scales for Children (Pedlow, Sanson, Prior, \& Oberklaid, 1993; Prior, Smart, Sanson, \& Oberklaid, 2000). An overview of the recruitment and assessment procedures for each trial are provided below.

\subsubsection{Cool Little Kids trial}

The CLK trial was aimed at community level prevention of child anxiety. A total of 545 parents were recruited to the trial through systematic screening for child inhibition across 307 preschool services in Melbourne, Australia. Participating parents were randomized to either a control or intervention condition. Intervention parents were offered the Cool Little Kids anxiety prevention program, which comprised six parenting group sessions delivered during the preschool year (for further details see Bayer et al., 2011, 2017). At one year post randomization, participating parents were invited to take part in a structured telephone interview of child anxiety diagnoses conducted by graduate psychology students trained by the CLK research team. Parents were also mailed a set of pen-and-paper questionnaires, which included the CALIS-PV. The present study uses data from the 443 (81\%) parents who 
completed the CALIS-PV at this one year follow-up assessment. One participant was excluded from analyses due to a marked outlying child age (child age $=8.3$ years, 6.0 SD above the CLK sample mean).

\subsubsection{Cool Little Kids Online trial}

The CLK-Online trial tested the efficacy of an online adaptation of the Cool Little Kids anxiety prevention program. A total of 433 parents of a temperamentally inhibited preschoolaged child were recruited to the trial via the CLK-Online website (www.coollittlekids.org.au). The trial was promoted to parents through Australia-wide online advertising, as well as flyers distributed to selected preschool services in the state of Victoria, Australia. Participating parents were randomly allocated to either a wait-list control or intervention condition, and intervention parents were provided access to the Cool Little Kids Online program for six months (for further details see Morgan et al., 2016, 2017). Follow-up assessments were conducted via an online survey at 12 weeks and 24-weeks post-randomization. The present study uses data from the 341 (79\%) parents who completed the CALIS-PV at the final 24week follow-up assessment. Four participants were excluded from analyses due to missing child age.

\subsection{Data analysis}

Before beginning primary analyses, the CLK and CLK-Online trial datasets were merged in SPSS 24, and item frequencies and inter-item correlations were inspected. Confirmatory factor analysis and measurement invariance tests were then conducted in MPlus 7.4 (Muthén \& Muthén, 1998-2012) using robust weighted least square (WLSMV) estimation for ordinal data. By default, MPlus handles missing data ( $<1 \%$ for all items) using a pairwise present approach with WLSMV estimation.

\subsubsection{Confirmatory factor analysis}


The three-factor structure previously validated for the school-age CALIS was tested via a CFA of the CALIS-PV items. Within this confirmatory factor model, each CALIS-PV item was allocated to an At Home, Outside Home or Parent Life interference factor, based on the primary factor loading for its corresponding item within the school-age CALIS. Three CALIS-PV items not included in the CALIS were allocated to the factor to which they seemed most appropriate. Goodness of fit to the data for the resulting CALIS-PV factor model was evaluated using the Comparative Fit Index (CFI), the Tucker-Lewis Index (TLI), and the Root Mean Square of Approximation (RMSEA) and its 90\% confidence interval (90\% CI). CFI and TLI values greater than .900 and .950 indicate acceptable and good model fit, respectively. RMSEA values can be classified as good $(<.06)$, acceptable (.06-.08), and mediocre (.08-.10), while models with an RMSEA > .10 should be rejected (Browne \& Cudeck, 1992; Little, 2013). Although the $\chi^{2}$ statistic is reported for the present study, interpretation of model fit relied on the above incremental fit indices due to the frequent rejection of adequate models in large samples using $\chi^{2}$ (West, Taylor, \& Wu, 2012).

As incremental fit indices did not uniformly suggest good fit for the initial CALIS-PV factor model, modification indices were inspected to identify sources of model misfit. Modification indices were implemented and tested iteratively. That is, the largest substantively meaningful modification index was first implemented, and the revised model was compared to the preceding (nested) model (Jöreskog, 1993). Nested models were compared using the Mplus DIFFTEST function (MD $\left.\Delta \chi^{2}\right)$, with $p<.01$ indicating significantly improved fit for the revised model. To minimize the risk of over-fitting to trivial features of the sample data, this process was continued only until adequate model fit was achieved, and the largest remaining modification index was not considered substantively important (Brown, 2014).

\subsubsection{Measurement invariance tests}


We tested invariance of the final CALIS-PV factor model across genders (girl vs. boy), age groups (3-4 years vs. 5-7 years), diagnostic groups (presence $v s$. absence of at least one anxiety disorder) and the two trial samples (CLK vs. CLK-Online). We began by estimating separate single-group CFA models for each subgroup, to confirm adequate factor loadings and model fit to the data. We then compared fit indices for increasingly restrictive multigroup CFA models to establish invariance of the overall factor structure (configural invariance), factor loadings (metric invariance) and item thresholds (scalar invariance) across groups (Cheung, 2008; Meredith \& Teresi, 2006). Comparisons of model fit for nested invariance models were based on changes to the incremental fit indices, in addition to $\operatorname{MD} \Delta \chi^{2}$. For each nested model comparison, a reduction of .010 or less in the CFI and TLI, and an increase of .015 or less in the RMSEA, was taken to indicate that the null hypothesis of measurement invariance should not be rejected (Chen, 2007; Cheung \& Rensvold, 2002).

\subsubsection{Internal consistency and validity tests}

Internal consistency of the CALIS-PV factors was assessed using McDonald's (1999) omega $(\omega)$ coefficient, with values above .70 considered satisfactory. The omega coefficient provides a model-based estimate of internal consistency that takes into account the magnitude of item factor loadings as well as any residual covariance between item pairs (Bentler, 2009). This approach has been shown to outperform alternative estimates such as Cronbach's alpha (Revelle \& Zinbarg, 2009; Zinbarg, Revelle, Yovel, \& Li, 2005).

Additional psychometric properties of the CALIS-PV factors were examined in SPSS. To establish discriminant validity of the factors, independent samples $t$ tests were conducted to compare factor scores for children with and without an anxiety diagnosis. Convergent and divergent validity of the CALIS-PV factors was examined using Pearson correlations between the CALIS-PV factors and closely associated constructs (i.e., child internalizing symptoms assessed via the PAS-R, CMFWQ and SDQ Emotional Problems subscale) and less 
associated constructs (i.e., externalizing symptoms assessed via the SDQ Hyperactivity and Conduct Problems subscales).

\section{Results}

\subsection{Preliminary analyses}

Parent responses spanned the full five-point Likert scale for each CALIS-PV item, with $5.3 \%$ (impact on the parent's relationship with extended family) to $52.1 \%$ (impact on the child's interactions with unfamiliar adults) endorsing "quite a bit" to "a great deal" on individual items. Few parents $(1 \%)$ reported no impacts of their child's anxiety on their own or their child's daily life. All inter-item correlations were significant $(r \mathrm{~s}=.16-.73, p<.001)$. While no correlations fell above conventional thresholds for item redundancy (Tabachnick \& Fidell, 2014), correlations between parent interference items consistently exceeded .50, suggesting that some items could be removed with minimal loss of information. In particular, two parent interference items ("your free time" and "the level of harmony in the family home") correlated $>.70$ with a number of other items. These two items were therefore removed prior to factor analysis, both for measure parsimony and for consistency with the school-age CALIS (see Section 2.2.1.).

\subsection{Confirmatory factor analysis}

Model fit statistics for all tested CFA models are represented under Models 1a to $2 \mathrm{~b}$ in Table 2. Incremental fit indices for the hypothesized three-factor model were mixed; the CFI and TLI were satisfactory $(\mathrm{CFI}=.949 ; \mathrm{TLI}=.941)$, while the confidence interval of the RMSEA suggested inadequate model fit to the data (RMSEA $=.099$ [90\% CI $=.094-.105])$. The two largest modification indices suggested correlated residuals for two item pairs (i.e., "getting along with parents" and "getting along with siblings"; "interacting with familiar 
adults" and "interacting with unfamiliar adults"). This indicates that the relationship between each item pair was not well accounted for by their shared factor. Given clear overlap for each item pair in terms of both wording and life domain assessed, each correlated residual was deemed to be substantively justified and was iteratively added to the factor model. The incorporated correlated residuals were significant and large (parent and sibling relationship item pair $r=.66$; interacting with adults item pair $r=.40$ ), and resulted in a significant improvement in model fit to the data $\left(\mathrm{MD} \Delta \chi^{2} p<.001\right)$. The next two largest modification indices suggested cross-loadings for the Parent Life item "going out with child" on both the child At Home and Outside Home factor. Such cross-loadings were not considered substantively important, and so were not implemented in the final model.

Incremental fit indices for the three-factor model incorporating two correlated residuals (Model 1c) indicated adequate fit to the data $(\mathrm{CFI}=.971 ; \mathrm{TLI}=.966 ; \mathrm{RMSEA}=.076[90 \%$ $\mathrm{CI}=.071-.082])$. As represented in Table 3, all standardized factor loadings were high $(\lambda=$ $.57-.89 ; M=.78)$. Inter-factor correlations were large $(r s=.75-.90, p<.001)$, suggesting little differentiation between the three factors. In light of these high factor correlations, two alternative and more parsimonious CFA models were tested to determine whether responses on the CALIS-PV would be best represented by a single "anxiety life interference" score. First, a one-factor model was tested in which all CALIS-PV items loaded onto a single anxiety life interference factor (Model 2a). This model showed inadequate fit to the data according to the RMSEA (RMSEA $=.119[90 \% \mathrm{CI}=.114-.124]$ ), and so was not investigated further. A second-order factor model was then tested in which the at home, outside home and parent life CALIS-PV factors loaded equally onto an overarching anxiety life interference factor (Model 2b). Incremental fit statistics for this second-order model met minimum standards for adequate model fit $(\mathrm{CFI}=.966$; $\mathrm{TLI}=.960 ; \mathrm{RMSEA}=.082[90 \% \mathrm{CI}$ $=.077-.087])$. However, the single-order three-factor model (Model 1c) provided 
significantly improved fit $\left(\mathrm{MD} \Delta \chi^{2} p<.001\right)$ relative to this second-order model. The singleorder three-factor model was therefore retained as the optimal CALIS-PV factor model.

\subsection{Measurement invariance tests}

Tests of measurement invariance for the final three-factor CALIS-PV model (Model 1c) were conducted for four sample groupings comprising two subgroups each: gender (girl $v s$. boy), age group (3-4 years vs. 5-7 years), diagnostic status (presence $v s$. absence of at least one anxiety disorder), and trial sample (CLK vs. CLK-Online). Model fit statistics for these measurement invariance tests are provided under Models 3a to 6c in Table 2. Initial singlegroup CFAs confirmed adequate model fit to the data for each of the eight subgroups $(\mathrm{CFI} / \mathrm{TLI}>$.900; RMSEA < .100). Multiple-group configural, metric and scalar invariance models also provided adequate fit to the data for each of the four groupings. In addition, metric and scalar invariance was demonstrated for genders, age groups and trial samples without any significant decrement of model fit $\left(\mathrm{MD} \Delta \chi^{2} p>.01 ; \Delta \mathrm{CFI} / \mathrm{TLI} \leq .010 ; \Delta \mathrm{RMSEA}\right.$ $\leq .015)$. For diagnostic groups, a significant $\chi^{2}$ difference (MD $\left.\Delta \chi^{2} p<.01\right)$ was observed between the configural and metric model. However, differences between the incremental fit indices for these two models were negligible $(\Delta \mathrm{CFI}=-.001 ; \Delta \mathrm{TLI}=.002 ; \Delta \mathrm{RMSEA}=-.001)$, indicating that the null hypothesis of measurement invariance should not be rejected (see Section 2.4.2; Chen, 2007; Chung et al., 2016). Thus, measurement invariance was supported for all four tested subgroups of the study sample.

\subsection{Internal consistency and validity tests}

Due to the high correlations between the CALIS-PV factors, internal consistency and validity tests were conducted for the total scale as well as individual factors. Internal consistency was adequate for each of the CALIS-PV factors (At Home $\omega=.77$; Outside Home $\omega=.87$; Parent Life $\omega=.94$ ) and the total scale (Total $\omega=.88)$. 
Discriminant validity of the three CALIS-PV factors and total scale was tested via independent samples $t$ tests comparing scores for children with and without an anxiety diagnosis. Differences were significant for each factor and the total scale for variances that were not assumed to be equal: At Home $t(644)=-12.33, p<.001$; Outside Home $t(695)=-$ $13.99, p<.001$, Parent Life $t(638)=-12.08, p<.001$, total scale $t(666)=-14.88, p<.001$. As the distributions for the At Home and Parent Life factor were slightly skewed (At Home skew $=1.09$; Parent Life skew $=1.05)$, tests for these two factors were repeated using the nonparametric Mann-Whitney test. Results were again significant for each factor at $p<.001$. For all three CALIS-PV factors and the total scale, scores were significantly higher for children with an anxiety diagnosis as compared to those without a diagnosis, with large effect sizes (Cohen's $d$ ) for the comparisons (see Table 4).

Convergent and divergent validity of the CALIS-PV factor scores and total scale score was examined via Pearson's correlations with measures of child internalizing and externalizing symptoms (see Table 5). All correlations were positive and significant $(p<$ .001). As expected, correlations for measures of internalizing symptoms (i.e., PAS-R, CMFWQ and SDQ Emotional Problems; $r s=.55-.72$ ) were consistently stronger than those for externalizing symptoms (i.e., SDQ Hyperactivity and Conduct Problems; $r$ s $=.28-.41$ ).

\section{Discussion}

The goal of this study was to test the psychometric properties of the CALIS-PV in a sample of temperamentally inhibited preschool-aged children. Confirmatory factor analysis of the CALIS-PV items replicated the three-factor structure of the original CALIS for schoolaged children and adolescents, with factors representing impacts of child anxiety in the home environment, outside the home environment, and on parent life. The three-factor CALIS-PV model provided adequate fit to the study data and showed invariance across key subgroups of the sample (i.e., girls and boys; children at the start and the end of the preschool 
developmental period, children with and without an anxiety diagnosis; the CLK trial sample and the CLK-Online trial sample). The three CALIS-PV factors demonstrated good internal consistency, and significant group differences were observed on all factors for children with and without an anxiety diagnosis. Convergent validity of the CALIS-PV factors was supported by moderate to strong correlations with conceptually related measures of internalizing symptoms. Correlations with less conceptually related measures of externalizing symptoms (i.e., hyperactivity and conduct problems) were consistently lower than those observed for internalizing symptoms, supporting divergent validity of the CALIS-PV. Previous early intervention studies have shown the CALIS-PV to be sensitive to treatment response (Kennedy et al., 2009; Morgan et al., 2017). Collectively these findings provide support for the CALIS-PV as a reliable and valid measure of anxiety life interference for preschool-aged children.

As noted by Lyneham et al. (2013), the distinction between impairments occurring at home and outside home in both the CALIS and CALIS-PV differs from most other measures of impairment, which tend to distinguish family, educational and social domains of functioning (e.g., the CAIS and CSDS). Discrepancies between a child's functioning inside and outside the home context are common in clinical practice. A socially anxious child may for example present as competent and outgoing in their home environment, but appear distressed and withdrawn in less familiar preschool and social contexts (Lyneham et al., 2013). Another child with separation fears may insist on sleeping with parents and express extreme distress at parental separations, causing significant disruption in the home context. The same child may however engage well once settled in preschool and social activities. The CALIS-PV factors are able to capture these potential differences between a child's functioning in and outside their familiar home environment. 
Factor analyses of the CALIS-PV clearly supported separate analysis of life interference occurring at home, outside home and in the parent's life. It should be noted however that observed factor correlations were markedly higher than those reported for the school-age CALIS. Separations between education, social and family life may be less pronounced during the preschool period, when parents hold considerable control over all areas of their child's life, and both preschool and extracurricular activities are largely focused on social development and enjoyment. The level of association between CALIS-PV factors in the present study certainly suggests little differentiation between the at home, outside home and parent life impacts of anxiety for preschool-aged children, at least according to parent report. This supports cautious use of the CALIS-PV total scale score in research contexts where the sole objective of assessment is to provide a parsimonious indicator of the severity of anxiety life interference.

The results of the present study must be interpreted with certain limitations in mind. First, the sample comprised parents of temperamentally inhibited children recruited for participation in an intervention trial. Temperamental inhibition is a key early marker of risk for anxiety problems, and is commonly used as a selection criterion for targeted anxiety prevention programs. Inhibited children therefore represent a critical group with which to validate the CALIS-PV. Further, prior research has highlighted considerable diversity in clinical outcomes among inhibited children (Degnan \& Fox, 2007), and this diversity was a key strength of present study. As would be expected in a temperamentally inhibited sample, social phobia was the most common child diagnosis. However, generalized anxiety disorder, separation anxiety disorder and specific phobia were also common, and approximately half of children did not meet criteria for an anxiety diagnosis. The obtained three-factor structure of the CALIS-PV fit the data equally well for children with and without an anxiety diagnosis, suggesting that the measure functions well across a range of anxiety symptom presentations. 
The current results nevertheless require replication in other samples to ensure validity of the CALIS-PV with anxious children who do not show temperamental inhibition.

A second limitation was that the present study sample over-represented educated dualparent families from an English-speaking background. Cross-cultural research suggests that the daily life impacts of child anxiety differ across different cultures. For instance, studies suggest fewer negative impacts of inhibited temperament and behaviors among children in China, as compared to children raised in Western individualistic cultures (such as North America and perhaps Australia) (Chen, Chen, Li, \& Wang, 2009; Chen, DeSouza, Chen, \& Wang, 2006). Daily life impacts of child anxiety may also differ for less advantaged and single parent families. Such families may for example have less time and resources to accommodate their child's anxiety (e.g., through allowing their child to stay home from preschool or accompanying their child throughout anxiety-provoking activities), leading to a different pattern of child and parent life impacts. Replication of the present study results with a focus on families of low socioeconomic status and from collectivist cultures would therefore be valuable.

A third limitation was that our assessment of the validity of the CALIS-PV was confined to parent-report measures included in the CLK and the CLK-Online trials from which our sample was drawn. Parents are an appropriate source of information about preschool anxiety as they are able to report on behavior over time and across multiple situations, and existing research indicates that they provide reliable assessments of child functioning (see Winters, Collett, \& Myers, 2005). Nevertheless, use of the same parent informant across assessments in the present study limits interpretation of the observed associations between the CALIS-PV factors and symptom measures. Research using multiple informants on both child symptoms and their functional impacts is required to further establish validity of the CALIS-PV. Such research should ideally examine associations 
between the CALIS-PV and alternative developmentally sensitive measures of impairment (for instance, life interference ratings for diagnoses assessed within the clinician-administered Preschool Age Psychiatric Assessment; Egger \& Angold, 2004).

Despite the above limitations, the present results support the CALIS-PV as a measure of the daily life impacts of preschool anxiety on both the child and their parent. To our knowledge, this is the first validation of a brief parent-report anxiety life interference measure designed specifically for use with preschool-aged children. The CALIS-PV fills an important gap in the current pool of developmentally sensitive anxiety assessments tools, and may be administered alongside symptom measures to provide a more comprehensive representation of a young child's anxiety. The measure may be useful in clinical practice to assist in determining overall case severity and prioritizing treatment goals with meaningful impacts for the child and their family. Given its brief parent-report format, the CALIS-PV may be used in both clinical and research contexts to efficiently monitor treatment progress and evaluate the effectiveness of anxiety interventions. It is hoped that the CALIS-PV will facilitate a greater focus on impairment from anxiety among preschool-aged children, and support further investigation of the complex relationship between anxiety symptoms and their impacts on daily life functioning.

\section{Acknowledgements}

This work used data from the Cool Little Kids (CLK) trial and the Cool Little Kids Online (CLK-Online) trial. CLK was supported by the Australian National Health and Medical Research Council [grant number 607302] and the Victorian Government's Operational Infrastructure Support Program. CLK-Online was supported by an Australian National Health and Medical Research Council Early Career Fellowship awarded to Dr. Morgan [fellowship number 1052544]. 
Conflict of Interest: The authors have no potential conflicts of interest to disclose. 


\section{References}

American Psychiatric Association. (2000). Diagnostic and Statistical Manual of Mental Disorders, Fourth Edition, Text Revision (DSM-IV-TR). Arlington, VA: American Psychiatric Association.

American Psychiatric Association. (2013). Diagnostic and Statistical Manual of Mental Disorders (DSM-5®). Arlington, VA: American Psychiatric Association.

Andrijic, V., Bayer, J., \& Bretherton, L. (2013). Validity of the Children's Moods, Fears and Worries Questionnaire in a clinical setting. Child and Adolescent Mental Health, 18(1), 11-17. doi:10.1111/j.1475-3588.2012.00655.x

Angold, A., Costello, E. J., Farmer, E. M. Z., Burns, B. J., \& Erkanli, A. (1999). Impaired but undiagnosed. Journal of the American Academy of Child \& Adolescent Psychiatry, 38(2), 129-137. doi:10.1097/00004583-199902000-00011

Antonucci, M., \& Bayer, J. K. (2017). Children's Moods, Fears and Worries Questionnaire: Validity with young children at risk for internalizing problems. Infant and Child Development, 26(2), e1966. doi:10.1002/icd.1966

Australian Bureau of Statistics. (2016). Education and work, Australia, 'Table 27 highest nonschool qualification: Bachelor degree level or above, persons aged 20-64 years, 2016', data cube: Excel spreadsheet, cat. no. 62270DO027_201605.

Bayer, J. K., Beatson, R., Bretherton, L., Hiscock, H., Wake, M., Gilbertson, T., . . Rapee, R. (2017). Translational delivery of Cool Little Kids to prevent child internalising problems: Randomised controlled trial. Australian \& New Zealand Journal of Psychiatry, 0004867417726582. doi:doi:10.1177/0004867417726582

Bayer, J. K., Rapee, R., Hiscock, H., Ukoumunne, O., Mihalopoulos, C., Clifford, S., \& Wake, M. (2011). The Cool Little Kids randomised controlled trial: Population-level early 
prevention for anxiety disorders. BMC Public Health, 11(1), 11. doi:10.1186/1471$2458-11-11$

Bayer, J. K., Sanson, A. V., \& Hemphill, S. A. (2006). Children's moods, fears, and worries. Journal of Emotional and Behavioral Disorders, 14(1), 41-49. doi:10.1177/10634266060140010401

Beesdo, K., Knappe, S., \& Pine, D. S. (2009). Anxiety and anxiety disorders in children and adolescents: Developmental issues and implications for DSM-V. Psychiatric Clinics of North America, 32(3), 483-524. doi:10.1016/j.psc.2009.06.002

Bentler, P. (2009). Alpha, dimension-free, and model-based internal consistency reliability. Psychometrika, 74(1), 137-143. doi:10.1007/s11336-008-9100-1

Bernstein, G. A., Bernat, D. H., Davis, A. A., \& Layne, A. E. (2008). Symptom presentation and classroom functioning in a nonclinical sample of children with social phobia. Depression and Anxiety, 25(9), 752-760. doi:10.1002/da.20315

Bittner, A., Egger, H. L., Erkanli, A., Jane Costello, E., Foley, D. L., \& Angold, A. (2007). What do childhood anxiety disorders predict? Journal of Child Psychology and Psychiatry, 48(12), 1174-1183. doi:10.1111/j.1469-7610.2007.01812.x

Broeren, S., \& Muris, P. (2008). Psychometric evaluation of two new parent-rating scales for measuring anxiety symptoms in young Dutch children. Journal of Anxiety Disorders, 22(6), 949-958. doi:10.1016/j.janxdis.2007.09.008

Brown, T. A. (2014). Confirmatory factor analysis for applied research: Guilford Publications.

Browne, M. W., \& Cudeck, R. (1992). Alternative ways of assessing model fit. Sociological Methods \& Research, 21(2), 230-258. doi:10.1177/0049124192021002005

Bufferd, S. J., Dougherty, L. R., Carlson, G. A., Rose, S., \& Klein, D. N. (2012). Psychiatric disorders in preschoolers: Continuity from ages 3 to 6. American Journal of Psychiatry, 169(11), 1157-1164. doi:10.1176/appi.ajp.2012.12020268 
Bufferd, S. J., Dougherty, L. R., Olino, T. M., Dyson, M. W., Carlson, G. A., \& Klein, D. N. (2016). Temperament distinguishes persistent/recurrent from remitting anxiety disorders across early childhood. Journal of Clinical Child \& Adolescent Psychology, 1-10. doi:10.1080/15374416.2016.1212362

Chen, F. F. (2007). Sensitivity of goodness of fit indexes to lack of measurement invariance. Structural Equation Modeling: A Multidisciplinary Journal, 14(3), 464-504. doi:10.1080/10705510701301834

Chen, X., Chen, H., Li, D., \& Wang, L. (2009). Early Childhood Behavioral Inhibition and Social and School Adjustment in Chinese Children: A 5-Year Longitudinal Study. Child Development, 80(6), 1692-1704. doi:10.1111/j.1467-8624.2009.01362.x

Chen, X., DeSouza, A. T., Chen, H., \& Wang, L. (2006). Reticent behavior and experiences in peer interactions in Chinese and Canadian children. Developmental Psychology, 42(4), 656. doi:10.1037/0012-1649.42.4.656

Cheung, G. W. (2008). Testing equivalence in the structure, means, and variances of higherorder constructs with structural equation modeling. Organizational Research Methods, 11(3), 593-613. doi:10.1177/1094428106298973

Cheung, G. W., \& Rensvold, R. B. (2002). Evaluating goodness-of-fit indexes for testing measurement invariance. Structural Equation Modeling: A Multidisciplinary Journal, 9(2), 233-255. doi:10.1207/S15328007SEM0902_5

Chung, H., Kim, J., Park, R., Bamer, A. M., Bocell, F. D., \& Amtmann, D. (2016). Testing the measurement invariance of the University of Washington Self-Efficacy Scale short form across four diagnostic subgroups. Quality of Life Research, 25(10), 2559-2564. doi:10.1007/s11136-016-1300-z 
Clauss, J. A., \& Blackford, J. U. (2012). Behavioral inhibition and risk for developing social anxiety disorder: A meta-analytic study. Journal of the American Academy of Child \& Adolescent Psychiatry, 51(10), 1066-1075. doi:10.1016/j.jaac.2012.08.002

Coplan, R. J., DeBow, A., Schneider, B. H., \& Graham, A. A. (2009). The social behaviours of inhibited children in and out of preschool. British Journal of Developmental Psychology, 27(4), 891-905. doi:10.1348/026151008X396153

Degnan, K. A., \& Fox, N. A. (2007). Behavioral inhibition and anxiety disorders: Multiple levels of a resilience process. Development and Psychopathology, 19(03), 729-746. doi:10.1017/S0954579407000363

Edwards, S. L., Rapee, R. M., Kennedy, S. J., \& Spence, S. H. (2010). The assessment of anxiety symptoms in preschool-aged children: The revised preschool anxiety scale. Journal of Clinical Child \& Adolescent Psychology, 39(3), 400 - 409. doi:10.1080/15374411003691701

Egger, H. L., \& Angold, A. (2004). The Preschool Age Psychiatric Assessment (PAPA): A structured parent interview for diagnosing psychiatric disorders in preschool children. In R. DelCarmen-Wiggins \& A. Carter (Eds.), Handbook of infant, toddler and preschool mental health assessment (pp. 223-243). Oxford: Oxford University Press.

Essau, C. A., Lewinsohn, P. M., Olaya, B., \& Seeley, J. R. (2014). Anxiety disorders in adolescents and psychosocial outcomes at age 30. Journal of Affective Disorders, 163, 125-132. doi:10.1016/j.jad.2013.12.033

Fabiano, G. A., \& Pelham, W. E. (2016). Impairment in children. In S. Goldstein \& J. A. Naglieri (Eds.), Assessing impairment: From theory to practice (pp. 71-89). Boston, MA: Springer US. 
Fisak, B. (2014). The prevention of anxiety in preschool-aged children: Development of a new program and preliminary findings. Mental Health \& Prevention, 2(1-2), 18-25. doi:10.1016/j.mhp.2014.07.001

Gazelle, H., \& Druhen-Shell, M. J. (2017). Profiles of anxious solitary children: Predicting longitudinal peer relations trajectories. Merrill-Palmer Quarterly, 63(2).

Goodman, R. (1997). The Strengths and Difficulties Questionnaire: A research note. Journal of Child Psychology and Psychiatry, 38(5), 581-586. doi:10.1111/j.14697610.1997.tb01545.x

Goodwin, R. D., Fergusson, D. M., \& Horwood, L. J. (2004). Early anxious/withdrawn behaviours predict later internalising disorders. Journal of Child Psychology and Psychiatry, 45(4), 874-883. doi:10.1111/j.1469-7610.2004.00279.x

Hawes, D. J., \& Dadds, M. R. (2004). Australian data and psychometric properties of the Strengths and Difficulties Questionnaire. Australian and New Zealand Journal of Psychiatry, 38(8), 644-651. doi:10.1111/j.1440-1614.2004.01427.x

Hoff, A. L., Kendall, P. C., Langley, A., Ginsburg, G., Keeton, C., Compton, S., . . Piacentini, J. (2015). Developmental differences in functioning in youth with social phobia. Journal of Clinical Child \& Adolescent Psychology, 1-9. doi:10.1080/15374416.2015.1079779

Jongerden, L., Simon, E., Bodden, D. H. M., Dirksen, C. D., \& Bögels, S. M. (2015). Factors associated with the referral of anxious children to mental health care: The influence of family functioning, parenting, parental anxiety and child impairment. International Journal of Methods in Psychiatric Research, 24(1), 46-57. doi:10.1002/mpr.1457

Jöreskog, K. G. (1993). Testing structural equation models. In K. A. Bollen \& J. S. Long (Eds.), Sage (Vol. 154, pp. 294-316). Newbury Park, CA. 
Kagan, J., Reznick, J. S., \& Snidman, N. (1988). Biological bases of childhood shyness. Science, 240(4849), 167-171.

Kennedy, S. J., Rapee, R. M., \& Edwards, S. L. (2009). A selective intervention program for inhibited preschool-aged children of parents with an anxiety disorder: Effects on current anxiety disorders and temperament. Journal of the American Academy of Child and Adolescent Psychiatry, 48(6), 602-609. doi:1097/CHI.0b013e31819f6fa9

Kessler, R. C., Berglund, P., Demler, O., Jin, R., Merikangas, K. R., \& Walters, E. E. (2005). Lifetime prevalence and age-of-onset distributions of dsm-iv disorders in the national comorbidity survey replication. Archives of General Psychiatry, 62(6), 593-602. doi:10.1001/archpsyc.62.6.593

Kremer, P., de Silva, A., Cleary, J., Santoro, G., Weston, K., Steele, E., . . Waters, E. (2015). Normative data for the Strengths and Difficulties Questionnaire for young children in Australia. Journal of Paediatrics and Child Health, 51(10), 970-975. doi:10.1111/jpc.12897

La Greca, A. M., \& Lopez, N. (1998). Social anxiety among adolescents: Linkages with peer relations and friendships. Journal of Abnormal Child Psychology, 26(2), 83-94. doi:10.1023/a:1022684520514

Langley, A. K., Bergman, R. L., McCracken, J., \& Piacentini, J. C. (2004). Impairment in childhood anxiety disorders: Preliminary examination of the Child Anxiety Impact Scale - Parent Version. Journal of Child and Adolescent Psychopharmacology, 14(1), 105-114. doi:10.1089/104454604773840544

Langley, A. K., Falk, A., Peris, T., Wiley, J. F., Kendall, P. C., Ginsburg, G., . . Piacentini, J. (2013). The Child Anxiety Impact Scale: Examining parent- and child-reported impairment in child anxiety disorders. Journal of Clinical Child \& Adolescent Psychology, 43(4), 579-591. doi:10.1080/15374416.2013.817311 
Little, T. D. (2013). Longitudinal structural equation modeling. New York: The Guildford Press.

Lyneham, H. J., Abbott, M. J., \& Rapee, R. M. (2007). Interrater reliability of the Anxiety Disorders Interview Schedule for DSM-IV: Child and parent version. Journal of the American Academy of Child and Adolescent Psychiatry, 46(6), 731-736. doi:10.1097/chi.0b013e3180465a09

Lyneham, H. J., \& Rapee, R. M. (2005). Agreement between telephone and in-person delivery of a structured interview for anxiety disorders in children. Journal of the American Academy of Child \& Adolescent Psychiatry, 44(3), 274-282. doi:10.1097/00004583200503000-00012

Lyneham, H. J., Sburlati, E. S., Abbott, M. J., Rapee, R. M., Hudson, J. L., Tolin, D. F., \& Carlson, S. E. (2013). Psychometric properties of the Child Anxiety Life Interference Scale (CALIS). Journal of Anxiety Disorders, 27(7), 711-719. doi:10.1016/j.janxdis.2013.09.008

Mazzone, L., Ducci, F., Scoto, M. C., Passaniti, E., D'Arrigo, V., \& Vitiello, B. (2007). The role of anxiety symptoms in school performance in a community sample of children and adolescents. BMC Public Health, 7(1), 347. doi:10.1186/1471-2458-7-347

McDonald, R. P. (1999). Test theory: A unified treatment. Mahwah, NJ: Lawrence Erlbaum Associates.

McLellan, L. F., Iverach, L., Kangas, M., \& et al. (2016). Youth Online Diagnostic Assessment. Sydney, Australia: Centre for Emotional Health, Macquarie University.

Meredith, W., \& Teresi, J. A. (2006). An essay on measurement and factorial invariance. Medical Care, 44(11), S69-S77. doi:10.1097/01.mlr.0000245438.73837.89

Merikangas, K. R., He, J.-P., Burstein, M., Swanson, S. A., Avenevoli, S., Cui, L., . . . Swendsen, J. (2010). Lifetime prevalence of mental disorders in US adolescents: 
Results from the National Comorbidity Survey Replication-Adolescent Supplement (NCS-A). Journal of the American Academy of Child \& Adolescent Psychiatry, 49(10), 980-989. doi:10.1016/j.jaac.2010.05.017

Mieloo, C., Raat, H., Oort, F. v., Bevaart, F., Vogel, I., Donker, M., \& Jansen, W. (2012). Validity and reliability of the Strengths and Difficulties Questionnaire in 5-6 year olds: Differences by gender or by parental education? PLOS ONE, 7(5), 1-8. doi:10.1371/journal.pone.0036805

Morgan, A. J., Rapee, R. M., \& Bayer, J. K. (2016). Prevention and early intervention of anxiety problems in young children: A pilot evaluation of Cool Little Kids Online. Internet Interventions, 4, 105-112. doi:10.1186/s13063-015-1022-5

Morgan, A. J., Rapee, R. M., Salim, A., Goharpey, N., Tamir, E., McLellan, L. F., \& Bayer, J. K. (2017). Internet-delivered parenting program for prevention and early intervention of anxiety problems in young children: Randomized controlled trial. Journal of the American Academy of Child \& Adolescent Psychiatry, 56(5), 417-425. doi:10.1016/j.jaac.2017.02.010

Morgan, A. J., Rapee, R. M., Tamir, E., Goharpey, N., Salim, A., McLellan, L. F., \& Bayer, J. K. (2015). Preventing anxiety problems in children with Cool Little Kids Online: Study protocol for a randomised controlled trial. Trials, 16(1), 507. doi:10.1186/s13063-015$1022-5$

Muris, P., \& Meesters, C. (2002). Symptoms of anxiety disorders and teacher-reported school functioning of normal children. Psychological Reports, 91(2), 588-590. doi:10.2466/pr0.2002.91.2.588

Muroff, J., \& Ross, A. (2011). Social disability and impairment in childhood anxiety. In D. McKay \& E. A. Storch (Eds.), Handbook of Child and Adolescent Anxiety Disorders (pp. 457-478): Springer New York. 
Muthén, L. K., \& Muthén, B. (1998-2012). Mplus User's Guide. Seventh Edition. Los Angeles, CA: Muthén \& Muthén.

Mychailyszyn, M. P., Mendez, J. L., \& Kendall, P. C. (2010). School functioning in youth with and without anxiety disorders: Comparisons by diagnosis and comorbidity. School Psychology Review, 39(1), 106-121.

National Mental Health Strategy. (2005). Australian Mental Health Outcomes and Classification Network: Strengths and Difficulties Questionnaire Training Manual (Vol. 2005). New South Wales: NSW Institute of Psychiatry.

Paulus, F., Backes, A., Sander, C., Weber, M., \& von Gontard, A. (2015). Anxiety disorders and behavioral inhibition in preschool children: A population-based study. Child Psychiatry \& Human Development, 46(1), 150-157. doi:10.1007/s10578-014-0460-8

Pedlow, R., Sanson, A., Prior, M., \& Oberklaid, F. (1993). Stability of maternally reported temperament from infancy to 8 years. Developmental Psychology, 29(6), 998-1007. doi:10.1037/0012-1649.29.6.998

Pickles, A., Rowe, R., Simonoff, E., Foley, D., Rutter, M., \& Silberg, J. (2001). Child psychiatric symptoms and psychosocial impairment: Relationship and prognostic significance. The British Journal of Psychiatry, 179(3), 230-235. doi:10.1192/bjp.179.3.230

Prior, M., Smart, D., Sanson, A., \& Oberklaid, F. (2000). Does shy-inhibited temperament in childhood lead to anxiety problems in adolescence? Journal of the American Academy of Child and Adolescent Psychiatry, 39, 461-468. doi:10.1097/00004583-20000400000015

Rapee, R. M., Bőgels, S. M., van der Sluis, C. M., Craske, M. G., \& Ollendick, T. (2012). Annual research review: Conceptualising functional impairment in children and 
adolescents. Journal of Child Psychology and Psychiatry, 53(5), 454-468. doi:10.1111/j.1469-7610.2011.02479.x

Rapee, R. M., \& Coplan, R. J. (2010). Conceptual relations between anxiety disorder and fearful temperament. New Directions for Child and Adolescent Development, 2010(127), 1731. doi:10.1002/cd.260

Rapee, R. M., Kennedy, S., Ingram, M., Kennedy, S. J., \& Sweeney, L. (2005). Prevention and early intervention of anxiety disorders in inhibited preschool children. Journal of Consulting and Clinical Psychology, 73(3), 488-497. doi:10.1037/0022-006X.73.3.488

Revelle, W., \& Zinbarg, R. E. (2009). Coefficients alpha, beta, omega, and the glb: Comments on Sijtsma. Psychometrika, 74(1), 145-154. doi:10.1007/s11336-008-9102-z

Rimm-Kaufman, S. E., \& Kagan, J. (2005). Infant predictors of kindergarten behavior: The contribution of inhibited and uninhibited temperament types. Behavioral Disorders, 30(4), 331-347. doi:10.1177/019874290503000409

Silverman, W. K., Saavedra, L. M., \& Pina, A. A. (2001). Test-retest reliability of anxiety symptoms and diagnoses with the Anxiety Disorders Interview Schedule for DSM-IV: Child and Parent Versions. Journal of the American Academy of Child \& Adolescent Psychiatry, 40(8), 937-944. doi:10.1097/00004583-200108000-00016

Spence, S. H., Rapee, R., McDonald, C., \& Ingram, M. (2001). The structure of anxiety symptoms among preschoolers. Behav Res Ther, 39(11), 1293-1316. doi:10.1016/s0005-7967(00)00098-x

Stringaris, A., \& Goodman, R. (2013). The value of measuring impact alongside symptoms in children and adolescents: A longitudinal assessment in a community sample. Journal of Abnormal Child Psychology, 41(7), 1109-1120. doi:10.1007/s10802-013-9744-x 
Swan, A. J., \& Kendall, P. C. (2016). Fear and missing out: Youth anxiety and functional outcomes. Clinical Psychology: Science and Practice, 23(4), 417-435. doi:10.1111/cpsp.12169

Sylvester, C., \& Pine, D. S. (2016). Anxiety disorders. Handbook of Preschool Mental Health: Development, Disorders, and Treatment, 137-163.

Tabachnick, B. G., \& Fidell, L. S. (2014). Using multivatiate statistics, sixth edition. Boston: Pearson.

Thompson-Hollands, J., Kerns, C. E., Pincus, D. B., \& Comer, J. S. (2014). Parental accommodation of child anxiety and related symptoms: Range, impact, and correlates. Journal of Anxiety Disorders, 28(8), 765-773. doi:10.1016/j.janxdis.2014.09.007

Towe-Goodman, N. R., Franz, L., Copeland, W., Angold, A., \& Egger, H. (2014). Perceived family impact of preschool anxiety disorders. Journal of the American Academy of Child \& Adolescent Psychiatry, 53(4), 437-446. doi:10.1016/j. jaac.2013.12.017

Victorian Government. (2016). The state of Victoria's children report 2013-14: A report on resilience and vulnerability within Victoria's children and young people. Melbourne: State of Victoria (Department of Education and Training).

Warnick, E. M., Bracken, M. B., \& Kasl, S. (2008). Screening efficiency of the Child Behavior Checklist and Strengths and Difficulties Questionnaire: A systematic review. Child and Adolescent Mental Health, 13(3), 140-147. doi:10.1111/j.1475-3588.2007.00461.x

Warren, S. L. (2007). Diagnosis of anxiety disorders in infants, toddlers, and preschool children. In W. E. Narrow, M. B. First, P. J. Sirovatka, \& D. A. Regier (Eds.), Age and gender considerations in psychiatric diagnosis (pp. 201-214). Arlington, VA: American Psychiatric Association. 
West, S. G., Taylor, A. B., \& Wu, W. (2012). Model fit and model selection in structural equation modeling. In R. H. Hoyle (Ed.), Handbook of structural equation modeling. New York, NY: The Guilford Press.

Whalen, D. J., Sylvester, C. M., \& Luby, J. L. (2017). Depression and anxiety in preschoolers: A review of the past 7 years. Child and Adolescent Psychiatric Clinics of North America. doi:10.1016/j.chc.2017.02.006

Whiteside, S. P. (2009). Adapting the Sheehan Disability Scale to assess child and parent impairment related to childhood anxiety disorders. Journal of Clinical Child \& Adolescent Psychology, 38(5), 721-730. doi:10.1080/15374410903103551

Wichstrøm, L., Belsky, J., Jozefiak, T., Sourander, A., \& Berg-Nielsen, T. S. (2014). Predicting service use for mental health problems among young children. Pediatrics, 133(6), 10541060. doi:10.1542/peds.2013-3184

Winters, N. C., Collett, B. R., \& Myers, K. M. (2005). Ten-year review of rating scales, VII: Scales assessing functional impairment. Journal of the American Academy of Child and Adolescent Psychiatry, 44(4), 309-338. doi:10.1097/01.chi.0000153230.57344.cd

Wood, J. J. (2007). Academic competence in preschool: Exploring the role of close relationships and anxiety. Early education and development, 18(2), 223-242. doi:10.1080/10409280701282868

Wood, J. J., Piacentini, J. C., Bergman, R. L., McCracken, J., \& Barrios, V. (2002). Concurrent validity of the anxiety disorders section of the Anxiety Disorders Interview Schedule for DSM-IV: Child and parent versions. Journal of Clinical Child \& Adolescent Psychology, 31(3), 335-342. doi:10.1207/S15374424JCCP3103_05

Woodward, L. J., \& Fergusson, D. M. (2001). Life course outcomes of young people with anxiety disorders in adolescence. Journal of the American Academy of Child and Adolescent Psychiatry, 40(9), 1086-1093. doi:10.1097/00004583-200109000-00018 
Zinbarg, R. E., Revelle, W., Yovel, I., \& Li, W. (2005). Cronbach's $\alpha$, Revelle's $\beta$, and McDonald's $\omega \mathrm{H}$ : Their relations with each other and two alternative conceptualizations of reliability. Psychometrika, 70(1), 123-133. doi:10.1007/s11336-003-0974-7 
Table 1

Diagnostic and demographic characteristics of the study samples

\begin{tabular}{|c|c|c|}
\hline & $\begin{array}{c}\text { CLK } \\
\text { Sample } \\
(\mathrm{N}=443)\end{array}$ & $\begin{array}{l}\text { CLK-Online } \\
\text { Sample } \\
(\mathrm{N}=341)\end{array}$ \\
\hline \multicolumn{3}{|l|}{ Child characteristics } \\
\hline Age in years, $M(S D)$ & $5.7(0.4)$ & $5.3(1.0)$ \\
\hline Female $^{\mathrm{a}}$ & $48.8 \%$ & $53.4 \%$ \\
\hline \multicolumn{3}{|l|}{ Anxiety diagnoses } \\
\hline Any anxiety disorder & $48.9 \%$ & $47.5 \%$ \\
\hline Generalized anxiety disorder & $14.2 \%$ & $12.9 \%$ \\
\hline Separation anxiety disorder & $18.8 \%$ & $22.0 \%$ \\
\hline Social Phobia & $31.0 \%$ & $32.4 \%$ \\
\hline Specific Phobia & $22.9 \%$ & $21.1 \%$ \\
\hline \multicolumn{3}{|l|}{ Parent characteristics } \\
\hline Age in years ${ }^{\mathrm{a}}, \mathrm{M}(\mathrm{SD})$ & $37.9(4.3)$ & $36.1(5.1)$ \\
\hline Is child's birth mother & $94.4 \%$ & $95.3 \%$ \\
\hline Has a tertiary degree ${ }^{a}$ & $68.0 \%$ & $66.5 \%$ \\
\hline \multicolumn{3}{|l|}{ Family characteristics } \\
\hline Both birth parents at home ${ }^{\mathrm{a}}$ & $92.1 \%$ & $88.3 \%$ \\
\hline English spoken at home ${ }^{a}$ & $89.6 \%$ & $95.0 \%$ \\
\hline Financial disadvantage (healthcare card) ${ }^{\mathrm{a}}$ & $15.9 \%$ & $13.2 \%$ \\
\hline
\end{tabular}

${ }^{a}$ Assessed at baseline. All other presented diagnostic and demographic information was assessed at follow-up. 
Table 2

Model fit statistics for all tested CFA and measurement invariance models of the Child Anxiety Life Interference Scale - Preschool Version

\begin{tabular}{|c|c|c|c|c|c|c|c|c|c|c|}
\hline Model & $\chi^{2}$ & $d f$ & CFI & TLI & RMSEA & $\begin{array}{c}\text { RMSEA } \\
90 \% \text { CI }\end{array}$ & $\operatorname{MD} \Delta \chi^{2}(d f)$ & $\Delta \mathrm{CFI}$ & $\Delta \mathrm{TLI}$ & $\triangle \mathrm{RMSEA}$ \\
\hline \multicolumn{11}{|l|}{1 Hypothesized 3-factor CFA model } \\
\hline 1a 3-factor & $1,156.404 * *$ & 132 & .949 & .941 & .099 & $.094-.105$ & & & & \\
\hline 1b 3-factor with $1 \mathrm{CR}$ & $862.700 * *$ & 131 & .964 & .958 & .084 & $.079-.090$ & $116.903 * *(1)$ & .015 & .017 & -.015 \\
\hline 1c 3-factor with 2 CRs & $719.568 * *$ & 130 & .971 & .966 & .076 & $.071-.082$ & $98.027 * *(1)$ & .007 & .008 & -.008 \\
\hline \multicolumn{11}{|l|}{2 Alternative tested CFA models } \\
\hline 2a 1 -factor with $2 \mathrm{CRs}$ & $1,614.091 * *$ & 133 & .927 & .916 & .119 & $.114-.124$ & & & & \\
\hline 2b Second-order 3-factor with $2 \mathrm{CRs}^{\mathrm{a}}$ & $829.032 * *$ & 132 & .966 & .960 & .082 & $.077-.087$ & $55.719 * *(2)$ & -.005 & -.006 & .006 \\
\hline \multicolumn{11}{|l|}{$\begin{array}{l}3 \text { Final retained CFA model (Model 1c), } \\
\text { Gender invariance }\end{array}$} \\
\hline 3a $\operatorname{Girl}(n=398)$ & $505.089 * *$ & 130 & .962 & .956 & .085 & $.077-.093$ & & & & \\
\hline 3 b Boy $(n=386)$ & $336.993 * *$ & 130 & .981 & .977 & .064 & $.056-.073$ & & & & \\
\hline \multirow{3}{*}{$\begin{array}{l}\text { 3c 1. Configural invariance } \\
\text { 2. Metric invariance } \\
\text { 3. Scalar invariance }\end{array}$} & $852.179 * *$ & 260 & .971 & .966 & .076 & $.071-.082$ & & & & \\
\hline & $868.382 * *$ & 275 & .971 & .968 & .074 & $.069-.080$ & $22.654(15)$ & .000 & .002 & -.002 \\
\hline & $844.920 * *$ & 326 & .975 & .977 & .064 & $.058-.069$ & $52.942(51)$ & -.004 & .009 & -.010 \\
\hline \multicolumn{11}{|l|}{$\begin{array}{l}4 \text { Final retained CFA model (Model 1c), } \\
\text { Age group invariance }\end{array}$} \\
\hline $4 \mathrm{a} \quad 3-4$ years $(n=143)$ & $262.466 * *$ & 130 & .962 & .955 & .084 & $.070-.099$ & & & & \\
\hline $4 \mathrm{~b} \quad 5-7$ years $(n=641)$ & $570.949 * *$ & 130 & .973 & .969 & .073 & $.067-.079$ & & & & \\
\hline \multirow{3}{*}{$\begin{array}{l}\text { 4c 1. Configural invariance } \\
\text { 2. Metric invariance } \\
\text { 3. Scalar invariance }\end{array}$} & $796.780 * *$ & 260 & .972 & .967 & .073 & $.067-.078$ & & & & \\
\hline & $798.759 * *$ & 275 & .973 & .970 & .070 & $.064-.075$ & $14.339(15)$ & .001 & .003 & -.003 \\
\hline & $777.787 * *$ & 326 & .977 & .978 & .059 & $.054-.065$ & $49.060(51)$ & .004 & .008 & -.011 \\
\hline \multicolumn{11}{|l|}{$\begin{array}{l}5 \text { Final retained CFA model (Model 1c), } \\
\text { Diagnostic group invariance }\end{array}$} \\
\hline 5a No anxiety diagnosis $(n=390)$ & $404.149 * *$ & 130 & .962 & .955 & .074 & $.065-.082$ & & & & \\
\hline $5 b \quad$ Anxiety diagnosis $(n=364)$ & $425.093 * *$ & 130 & .960 & .953 & .079 & $.071-.087$ & & & & \\
\hline 5c 1. Configural invariance & $829.613 * *$ & 260 & .961 & .954 & .076 & $.070-.082$ & & & & \\
\hline 2. Metric invariance & $852.424 * *$ & 275 & .960 & .956 & .075 & $.069-.080$ & $31.678 *(15)$ & -.001 & .002 & -.001 \\
\hline
\end{tabular}




\begin{tabular}{|c|c|c|c|c|c|c|c|c|c|c|c|}
\hline \multicolumn{2}{|c|}{ Model } & \multicolumn{10}{|c|}{ RMSEA } \\
\hline & 3. Scalar invariance & $837.462 * *$ & 326 & .965 & .967 & .065 & $.059-.070$ & $69.000(51)$ & .005 & .011 & -.010 \\
\hline \multicolumn{12}{|c|}{$\begin{array}{l}6 \text { Final retained CFA model (Model 1c), } \\
\text { Trial sample invariance }\end{array}$} \\
\hline $6 a$ & $\operatorname{CLK}(n=443)$ & $431.455^{* *}$ & 130 & .970 & .965 & .072 & .065-.080 & & & & \\
\hline $6 \mathrm{~b}$ & CLK-Online $(n=341)$ & $379.137 * *$ & 130 & .972 & .967 & .075 & .066-.084 & & & & \\
\hline \multirow[t]{3}{*}{$6 c$} & 1. Configural invariance & $812.206^{* *}$ & 260 & .970 & .965 & .074 & .068-.079 & & & & \\
\hline & 2. Metric invariance & $826.086^{* *}$ & 275 & .970 & .967 & .071 & 然66-.077 & $22.382(15)$ & .000 & .002 & -.003 \\
\hline & 3. Scalar invariance & $812.617^{* *}$ & 326 & .974 & .976 & .062 & .056-.067 & $62.338(51)$ & .004 & .009 & -.009 \\
\hline
\end{tabular}

Note. Boldface indicates the final retained model. CFA $=$ confirmatory factor analysis; $\mathrm{CR}=$ correlated residual; $\chi^{2}=$ Chi square test of model fit and its associated degrees of freedom $(d f)$; CFI = Comparative Fit Index; TLI = Tucker-Lewis Index; RMSEA = root mean square error of approximation and its $90 \%$ confidence interval $(\mathrm{CI})$;

$\mathrm{MD} \Delta \chi_{2}=$ Chi square difference test calculated with the Mplus DIFFTEST function for the robust weighted least square estimator (WLSMV); $\Delta=$ change relative to the preceding model. $N=754-784$.

${ }^{a}$ Model comparison statistics (i.e, MD $\Delta \chi^{2}, \Delta \mathrm{CFI}, \Delta \mathrm{TLI}, \Delta \mathrm{RMSEA}$ ) represent change relative to the final retained model (Model 1c). All other model comparison statistics represent change relative to the preceding model in the table.

$* p<.01 ; * * p .001$. 
Table 3

Standardized factor loadings and factor correlations for the 3-factor model of the Child Anxiety Life Interference Scale - Preschool Version

\begin{tabular}{cccc}
\hline Factor (Item) & \multicolumn{3}{c}{ Factor loadings } \\
\cline { 2 - 4 } & 1 & 2 & 3 \\
\hline
\end{tabular}

Factor 1: At Home

Child separating from parents (11) .76

Child distress (1) .75

Child daily activities (10) .73

Child parent relationship (2) .70

Child sibling relationship (3) .64

Factor 2: Outside Home

Child preschool activities (7) .89

Child enjoyable activities (9) .86

Child outside school activities (8) .85

Child interacting with preschool peers (4) .80

Child interacting with familiar adults (5) .65

Child interacting with unfamiliar adults (6) .57

Factor 3: Parent Life

Parent relationship with friends (14)

Parent going out with child (18)

Parent stress level (19)

Parent relationship with partner (12)

Parent going out without child (17)

Parent relationship with extended family (13)

Parent career (15)

Factor correlations

Factor 1: At Home

Factor 2: Outside Home .75

Factor 3: Parent Life

.90 .86

Note: All factor loadings and correlations significant at $p<.001$. 
Table 4

Descriptive statistics and effect sizes for the factor scores on the Child Anxiety Life

Interference Scale - Preschool Version for children with and without an anxiety diagnosis

\begin{tabular}{lcccc}
\hline & $\begin{array}{c}\text { Factor Score } \\
\text { Range }\end{array}$ & $\begin{array}{c}\text { No Diagnosis } \\
M(\mathrm{SD}) \\
n=390\end{array}$ & $\begin{array}{c}\text { Diagnosis } \\
M(\mathrm{SD}) \\
n=363-4\end{array}$ & $\begin{array}{c}\text { Effect size } \\
d(95 \% \mathrm{CI})\end{array}$ \\
\hline At Home & $0-20$ & $3.2(2.8)$ & $6.4(4.0)$ & $0.9(0.7-1.2)$ \\
Outside Home & $0-24$ & $7.4(4.1)$ & $12.1(5.1)$ & $1.0(0.7-1.4)$ \\
Parent Life & $0-28$ & $4.1(4.5)$ & $9.0(6.5)$ & $0.9(0.5-1.3)$ \\
Total Score & $0-72$ & $14.7(9.9)$ & $27.5(13.4)$ & $1.1(0.3-1.9)$ \\
\hline
\end{tabular}


Table 5

Correlations between the factor scores on the Child Anxiety Life Interference ScalePreschool Version and measures of child internalizing and externalizing symptoms

\begin{tabular}{lccccc}
\hline & $\begin{array}{c}\text { PAS-R } \\
n=341\end{array}$ & $\begin{array}{c}\text { CMFWQ }^{\mathrm{b}} \\
n=441-2\end{array}$ & $\begin{array}{c}\text { SDQ-Emo } \\
n=781-2\end{array}$ & $\begin{array}{c}\text { SDQ-Hyp } \\
n=782-3\end{array}$ & $\begin{array}{c}\text { SDQ-Con } \\
n=781-2\end{array}$ \\
\hline At Home & $.66^{*}$ & $.62^{*}$ & $.64^{*}$ & $.37^{*}$ & $.41^{*}$ \\
Outside Home & $.69^{*}$ & $.61^{*}$ & $.58^{*}$ & $.29^{*}$ & $.28^{*}$ \\
Parent Life & $.59^{*}$ & $.56^{*}$ & $.55^{*}$ & $.38^{*}$ & $.37^{*}$ \\
Total Score & $.72^{*}$ & $.68^{*}$ & $.66^{*}$ & $.39^{*}$ & $.39^{*}$ \\
\hline
\end{tabular}

Note: PAS-R, Preschool Anxiety Scale Revised; CMFWQ, Children's Moods Fears and Worries Questionnaire; SDQ-Emo, Strengths and Difficulties Questionnaire Emotional Problems subscale; SDQ-Hyp, Strengths and Difficulties Questionnaire Hyperactivity subscale; SDQ-Con, Strengths and Difficulties Questionnaire Conduct Problems subscale.

${ }^{a}$ Measure administered to the CLK-Online sample only.

${ }^{\mathrm{b}}$ Measure administered to the CLK sample only

$* p<.001$. 